\title{
A Study on User Satisfaction of Vertically Extended Buildings
}

\author{
Lee, Chang-Jae ${ }^{1, a}$ Lim, Seok-ho ${ }^{2, b}$ \\ ${ }^{1}$ Research Fellow, Korea Institute of Civil Engineering and Building Technology, \\ South Korea \\ ${ }^{2}$ Senior Research Fellow, Korea Institute of Civil Engineering and Building Technology, \\ South Korea \\ avolgary@kict.re.kr, ${ }^{b}$ shlim@kict.re.kr
}

\begin{abstract}
Keywords: Satisfaction, Remodeling, Extension, User, residence, Prefabricated, Insulation.
Abstract. The present study aimed to serve as fundamental data for improving user convenience at the initial consulting stage of future extension and remodeling of buildings. In order to analyze the users' degree of satisfaction on existing extended buildings, we analyzed the evaluation characteristics in each category of entire building appearance, interior and exterior material conditions, indoor environment and construction period. The analysis results showed that it is important to ensure the unity among existing buildings in the extension of public buildings within the residential complex, and the use of heterogeneous materials with existing buildings, including lightweight frame panel (aka, sandwich panel) is to be avoided. Also, it is necessary to use interior and exterior materials that can compensate for this and employ a system that can substitute the RC rigid frames and lightweight panel frame system frequently used in existing extension and remodeling because it was shown that degree of satisfaction of soundproofing and insulation performance among indoor environment performance is considerably low compared to the other categories for most users who use existing extension floors.
\end{abstract}

\section{Introduction}

Recently, more attention is given on extending and remodeling existing buildings instead of constructing a new building due to recession in the property market. In fact, there are noticeable progress establishing measures to extend and remodel old buildings that were constructed 20 30 years ago. Most of the measures try to improve the environmental performance of the old buildings by minimizing energy consumption and increasing the area according to building owner's demand. The remodeling plan should be based on the satisfaction analysis of the residents and users. However, most of the plans are based on construction costs, intention of the building owner, and business even though it is important to set a plan that considers the users in the extension and remodeling of existing buildings as much as the new buildings. Consequentially, such approach may cause dissatisfaction of the users because consideration of users' who spend a lot of time in the building after the extension or remodeling was omitted. Therefore, this study aims to analyze the user satisfaction of extended buildings by considering the user demand and use it as the base data in planning extension and remodeling of residential and general buildings in order to solve such problems.

\section{Scope and method}

In this study, a public building located within the residential area was selected and a survey (5 point scale), in the form of interview, was conducted every day from 1 5pm from 20 January 2013 to 2 February 2013 in order to evaluate the satisfaction of the users of extended as well as remodeled buildings. The study area was limited to public buildings located within the residential area around Seoul and 70 surveys were distributed to people who use vertically extended part of the building. In total, 62 surveys contents were analyzed excluding 8 incomplete and unanswered surveys. 


\section{Satisfaction evaluation of remodeled buildings}

The subject of this study was users of apartments within residential areas of Seoul. The buildings that had vertical extensions from the rooftop were selected and preliminary investigation was conducted to survey four buildings (Building A- light steel structure, Building B-RC rahmen structure, Building C-light framework panel, Building D-light steel structure) with RC rahmen structure, light steel structure, light framework panel.

In total, 15 questions were used to evaluate the user satisfaction of extended public buildings within the residential area.

The survey consisted of six sections: social characteristics (5), entire building exterior (5), finishing material (2), indoor environment (4), construction period (2), and overall satisfaction (1). It was conducted by five researchers in the field of construction by personally visiting the study site. The collected data was processed by using Windows SPSS Ver. 18 Statistics Program.

Table 1. Details of Selected Building Structures

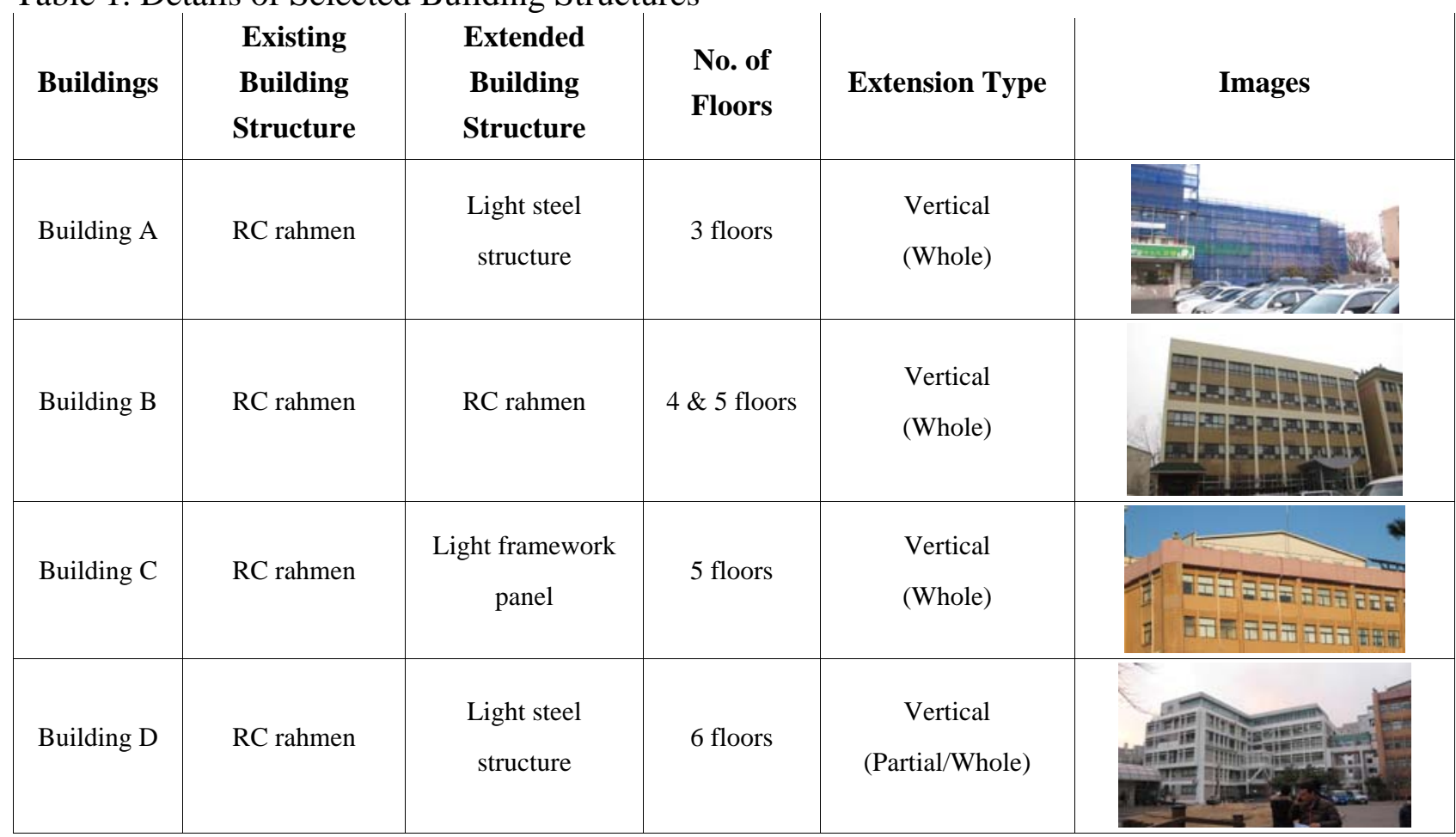

\section{1) Social characteristics}

The characteristics were male (58.1\%) and female (41.9\%) showing following distribution of age groups: 20s (22.6\%), 30s (22.6\%), 40s (30.6\%), 50s (17.7\%), 60s (6.5\%). The usage hours were the highest in 3 4 hours (43.5\%) followed by $5 \sim 6$ hours (32.3\%), 1 2 hours (16.1\%), less than 1 hour (4.8\%), and more than 1 9 hours (3.2\%)

\section{2) Entire building appearance}

Buildings appearance is an element that shows and creates the image of the city. The appearance of public building within residential area especially can represent the characteristics of the area or the complex. The appearance satisfaction of extended buildings in the study area were: Not so good (38.7\%), Not satisfied (32.3\%), Satisfied (22.6\%), Very not satisfied (6.5\%). Overall, the users were unsatisfied with the appearance of the building. The analysis of each building showed the highest satisfaction in building B (RC rahmen structure) with average satisfaction of 3.5, whereas building $\mathrm{C}$ (light weight panel) showed the lowest average satisfaction of 2.6. It was determined that the difference in the material used for extension from the existing building caused user satisfaction to decrease. 


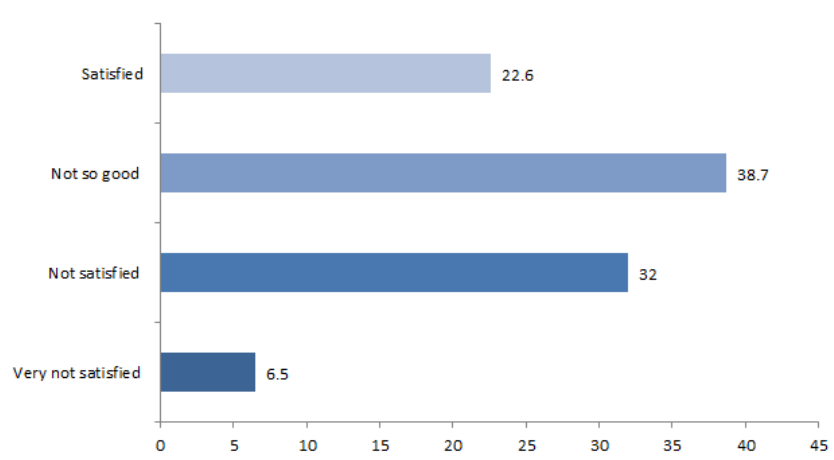

Fig 1. Entire building view

\section{3) Extended building finishing material satisfaction}

Two questioned were allocated to analyze the satisfaction on finishing material of extended floors and the satisfaction was analyzed according to the condition of exterior and internal finishing material. The satisfaction of exterior finishing material was: Not satisfied (40.3\%), Not so good (27.4\%), Very not satisfied (17.7\%), Satisfied (8.1\%), and Very satisfied (6.5\%) showing overall dissatisfaction. The condition of the exterior finishing material is an element closely related to the appearance of the building as a whole.

The most recent building, building $\mathrm{D}$, showed the highest satisfaction and building $\mathrm{B}$ ( $\mathrm{RC}$ rahmen structure) showed relative high satisfaction among the investigated buildings. The satisfaction of interior finishing material was: Not so good (30.6\%), Not satisfied (29.0\%), Very not satisfied (19.4\%), Satisfied (16.1\%), Very satisfied (4.8\%) showing relatively negative answers compared with condition of exterior material.

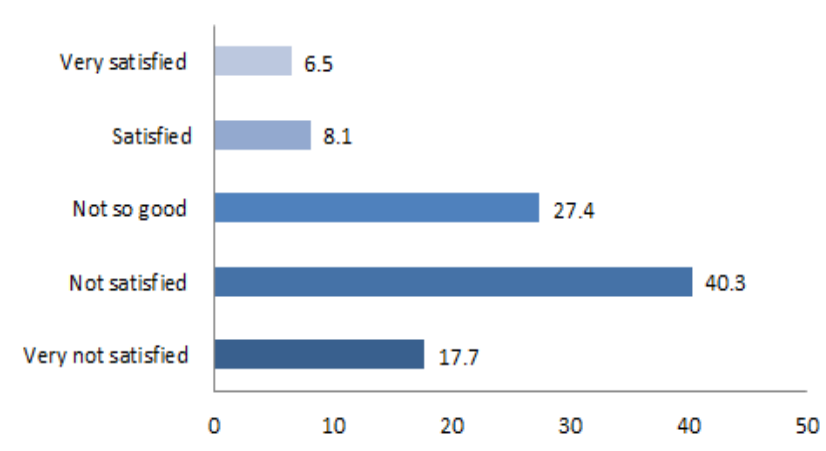

Fig 2. Exterior finishing material

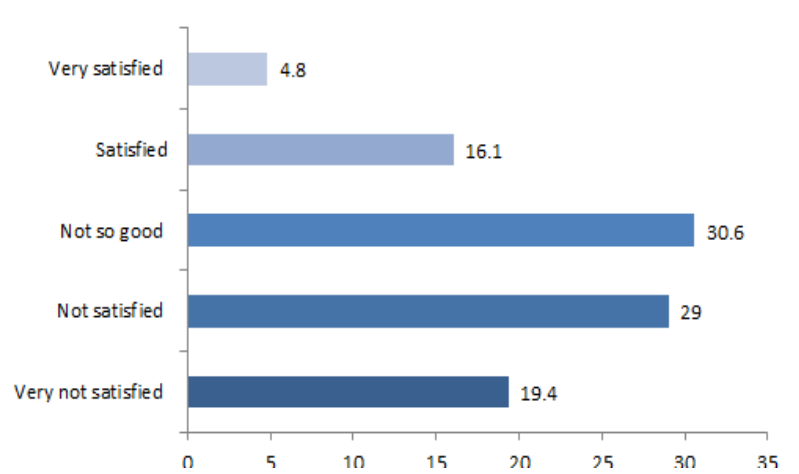

Fig 3. Indoor environment satisfaction

\section{4) Indoor environment satisfaction}

Four questions on lighting, ventilation, insulation, and soundproof were allocated to analyze the indoor environment satisfaction of extended buildings. There were more positive answers than negative answers on satisfaction of ventilation. The satisfaction on lighting was the lowest in building A which had fake wall installed in extended floors whereas building B had the highest satisfaction as it has highest ratio of window area.

There were overall negative answers with regards to the satisfaction of insulation and soundproof. It was analyzed that the extension of building A and B constructed using light weight framework panel had significantly low satisfaction. It was evident that air tightness declined in the extension constructed with light weight framework panel. The infrared thermal camera was used in parallel with the survey in order to inspect air tightness of the walls and it showed that the heat was leaking as shown. The satisfaction on soundproof was: Not so good (43.5\%), Not satisfied (22.6\%), Satisfied (19.4\%), Very not satisfied (12.9\%), Very satisfied (1.6\%). However, building D and building B (RC structure) which are used for exercise and volunteer work showed relatively high satisfaction. 


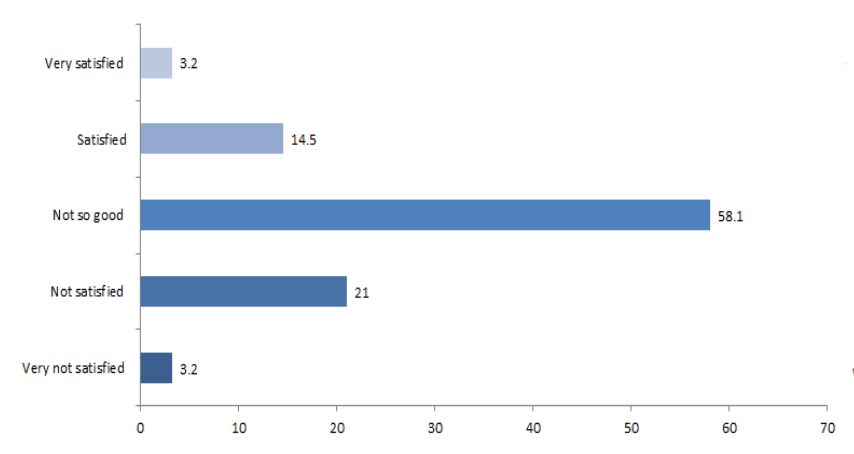

Fig 4. Lighting

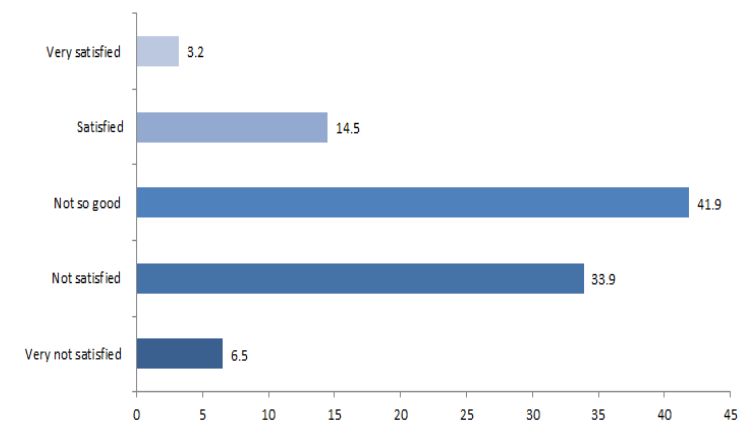

Fig 6. Insulation

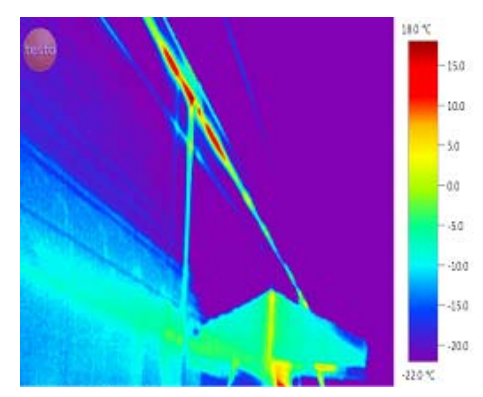

Fig 8. Exterior(Left) and Interior(Right) infrared thermal image(Right)

\section{5) Construction period satisfaction}

Two questions were allocated to analyze the satisfaction on construction period and degree of disturbance. The construction period and its degree of disturbance showed high number of negative answers and satisfaction of users in each building showed similar distribution. The lowest satisfaction on construction period and degree of disturbance was shown in building A which is currently under construction.

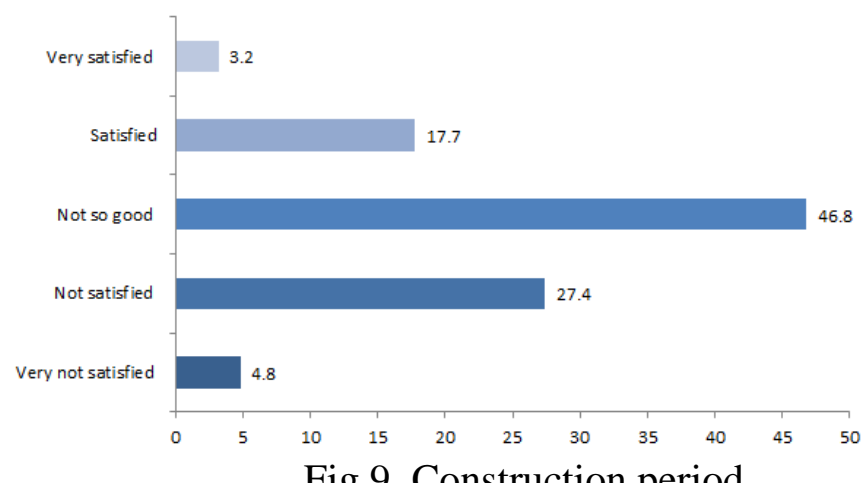

Fig 9. Construction period

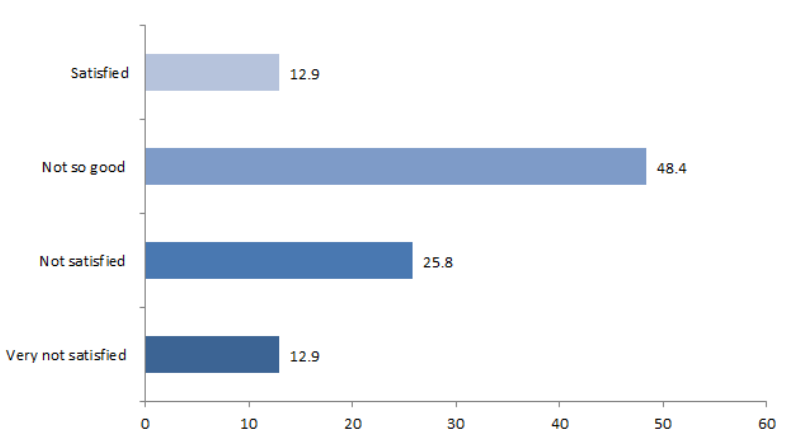

Fig 10. Degree of disturbance 


\section{6) Overall satisfaction}

The overall distribution of satisfaction was: Not satisfied (33.9\%), Not so good (33.9\%), Satisfied (24.2\%), Very not satisfied (4.8\%), Very satisfied (3.2\%) showing general negative views on extended floors. The satisfaction of building $\mathrm{D}$ was average 4.17 showing the highest overall satisfaction followed by building B (3.13), building C (2.3), and building A (2.25).

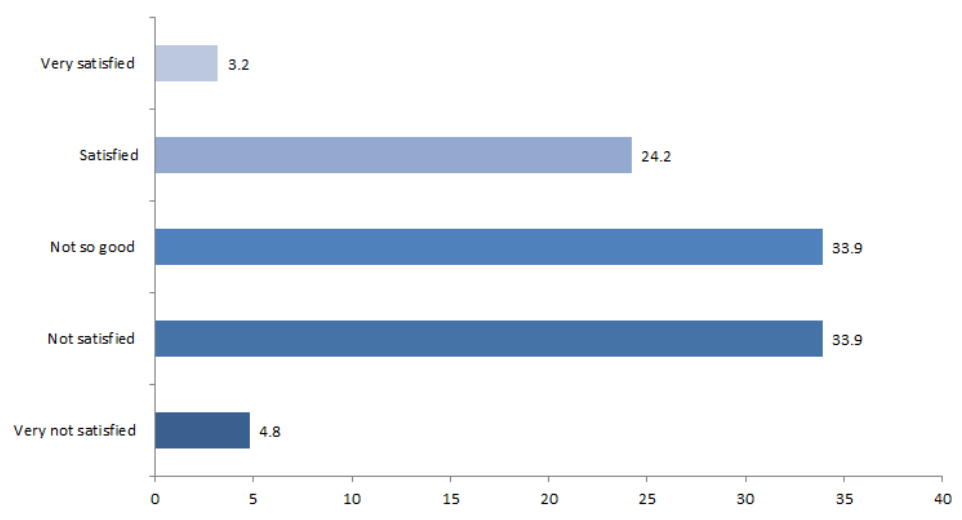

Fig 11. Overall satisfaction

It is thought that building D had the highest overall satisfaction because it was recently extended comprising of exercise facility and volunteer work rooms which has short usage hours. On contrary, it seems that building A and C, constructed using light weight framework panel and sandwich panel, had the lowest satisfaction because it is influenced by overall building appearance, interior and exterior material, and environmental functions.

\section{7) Influence analysis on user satisfaction}

Multiple regression analysis was performed to analyze the influence of elements, set as independent variable, used to determine satisfaction on overall satisfaction which was set as dependent variable. In addition, Durbin-Watson test was performed to test the independence and stepwise method was used for variables.

Table 2. Influence analysis of components

\begin{tabular}{|c|c|c|c|c|c|c|}
\hline & \multirow{2}{*}{ Models } & \multicolumn{2}{|c|}{ Non-standard coefficient } & \multirow{2}{*}{$\begin{array}{c}\text { Standard coefficient } \\
\text { Beta }\end{array}$} & \multirow[b]{2}{*}{$\mathrm{t}$} & \multirow{2}{*}{$\begin{array}{r}\text { Significance } \\
\text { probability }\end{array}$} \\
\hline & & B & $\begin{array}{l}\text { Standard } \\
\text { deviation }\end{array}$ & & & \\
\hline \multirow{10}{*}{ Items } & - & -.175 & .393 & & -.446 & .657 \\
\hline & Exterior material & -.138 & .088 & -.158 & -1.572 & .122 \\
\hline & Interior material & -.032 & .091 & -.038 & -.350 & .728 \\
\hline & Overall appearance & .210 & .103 & .195 & 2.044 & .046 \\
\hline & Lighting & -.063 & .109 & -.053 & -.580 & .564 \\
\hline & Ventilation & .047 & .101 & .046 & .472 & .639 \\
\hline & Insulation & .504 & .117 & .480 & 4.297 & .000 \\
\hline & Soundproof & .235 & .112 & .241 & 2.102 & .040 \\
\hline & Construction period & .125 & .102 & .115 & 1.229 & .225 \\
\hline & Degree of disturbance & .190 & .100 & .175 & 1.887 & .065 \\
\hline
\end{tabular}

$R^{2}=.680$, Adj- $R^{2}=.624, \mathrm{~F}(\mathrm{p})=12.261$, Durbin-Watson=1.867 
It was analyzed that elements which affect overall satisfaction had significant influence on 'overall appearance,' 'insulation,' and 'soundproof' but the overall satisfaction increased as the satisfaction of these three questions increased. The result implies that overall building appearance and indoor conditions, closely related to insulation and soundproof, significantly influence user satisfaction.

\section{Conclusion}

This study analyzed the user satisfaction of extended buildings in order to use the information as the base data for future extension and remodeling. The survey was divided into overall building appearance, conditions of interior and exterior material, indoor environment, and construction period, to analyze the evaluation characteristics per element. The following result was obtained from the analyzed data. It was found that it is important to use material that is consistent with the existing material when extending the public building in residential area. Also, the usage of light weight framework panel (sandwich panel), which are used widely to reduce the cost and period of construction, should be limited as they are inconsistent with the materials used in existing building. Majority of people using the existing extended floors showed high dissatisfaction on insulation and soundproof which were significantly low compared to other items. Therefore, exterior and interior materials that can supplement such dissatisfaction should be used. Lastly, a method that can replace RC rahmen structure and light weight framework panel frequently used in extension and remodeling should be introduced.

\section{Acknowledgement}

This study was carried out with financial support from the research project titled " OneDay Housing of Construction Technology Development, 2015"carried out by the Korea Institute of Civil Engineering and Building Technology.

\section{Reference}

[1] Baek, S., \& Lee, Y. (2011). Developing an application for prefabrication panel system based on Building Information Modeling, Proceeding of autumn Annual Conference of Architectural Institute of Korea,

[2] Cha, S., \& Lee, JH.(2012). A study on the current of law for apartment house community facilities for activation of the local community. Proceeding Spring Annual Conference of Urban Design Institute of korea

[3] Lee, G., \& Lim, S. (2011), A Study on Unit Modular Design Method of Urban-type Housing, Journal of the Housing Association Vol. 22

[4] Lim, S. H. et al. (2006), A comparative study on environmentally friendly unit modular residence factory production system, Korea Institute of Ecological Architecture and Environment Symposium Vol. 11

[5] Yoon, S., \& Park, N., \& Choi, J. (2009). A BIM-based Design Method for Energy-Efficient Housing , Proceeding of Spring Annual Conference of KHA 